\title{
An Evaluation of River Health for the Weihe River in Shaanxi Province, China
}

\author{
Jinxi Song, ${ }^{1,2}$ Dandong Cheng, ${ }^{2}$ Qi Li, ${ }^{2}$ Xingjun He, ${ }^{3}$ Yongqing Long, ${ }^{2}$ and Bo Zhang ${ }^{2}$ \\ ${ }^{1}$ State Key Laboratory of Soil Erosion and Dryland Farming on the Loess Plateau, Institute of Soil and Water Conservation, \\ CAS \& MWR, Yangling 712100, China \\ ${ }^{2}$ College of Urban and Environmental Sciences, Northwest University, Xian 710027, China \\ ${ }^{3}$ Shenzhen Green Island Environmental Water Technology Co., Ltd, Shenzhen 518108, China \\ Correspondence should be addressed to Jinxi Song; jinxisong@nwu.edu.cn
}

Received 15 December 2014; Accepted 3 February 2015

Academic Editor: Yongqiang Zhang

Copyright ( $\odot 2015$ Jinxi Song et al. This is an open access article distributed under the Creative Commons Attribution License, which permits unrestricted use, distribution, and reproduction in any medium, provided the original work is properly cited.

Excessive socioeconomic activities in the Weihe River region have caused severe ecosystem degradation, and the call for the recovery and maintenance of the river health has drawn great attention. Based on the connotation of river health, previous research findings, and status quo of the Weihe River ecosystem, in this study, we developed a novel health evaluation index system to quantitatively determine the health of the Weihe River in Shaanxi Province. The river in the study area was divided into five reaches based on the five hydrological gauging stations, and appropriate evaluation indices for each river section were selected according to the ecological environmental functions of that section. A hybrid approach integrating analytic hierarchy process (AHP) and a fuzzy synthetic evaluation method was applied to measure the river health. The results show that Linjiancun-Weijiabao reach and WeijiabaoXianyang reach are in the "moderate" level of health and Lintong-Huaxian reach and downstream of Huaxian reach are in the "poor" health rating, whereas Xianyang-Lintong reach is in the "sick" rating. Moreover, the most sensitive factors were determined, respectively, for each reach from upper stream to lower stream in the study area.

\section{Introduction}

From an economic point of view, water resources are composite assets that provide a variety of goods and services for consumptive and productive activities of human being $[1,2]$. Water is an essential resource for the existence of both human and other species on the earth [3]. In recent years, the concept of environmental flow (E-flow) has received increasing awareness; common understanding has come to recognize the importance of preserving some amount of water in a river to maintain the health of a river ecosystem [4-7].

However, the problems of water scarcity and deteriorating water quality, due to rapid socioeconomic development $[1,8]$ and climate change [9], have become more serious around the world, resulting in an increase in water demand for socioeconomic sectors and reduction in E-flow [7]. The survey results of the United Nations Environment Programme (UNEP) on
25 rivers reveal that water quality of the major rivers in the world is poor and deteriorated, and water quantity in the rivers is decreasing [10]. It is estimated that, in 2025, 5 billion out of the world's 7.9 billion people will be living in areas where it will be difficult or even impossible to meet basic water demand for drinking, cooking, and sanitation $[3,11]$.

Catchment and riparian degradation has caused declining ecosystem health of streams worldwide [12]. Many studies on river health evaluation have been conducted in order to prevent river ecosystem from further deterioration [1318]. For example, the declines and improvements in river health related to land use have been studied by using macroinvertebrates sampled from sites along a dry-land river in northwestern Zimbabwe to assess biotic responses to land use changes along the course of the river [19]. Water quality index, biotic index, and physical habitat quality index have been used to assess river health conditions using 25 sampling sites in the Liao River in China [20]. Biological monitoring, 
using coliform bacteria and macroinvertebrate populations and diversity, was carried out monthly to determine the ecological health of the Usuthu and Mbuluzi rivers in Swaziland [21]. Sheldon et al. [12] identified the spatial scale of land use that most strongly influenced overall river ecosystem health score in Southeast Queensland, Australia, in which the five component indicators (fish, macroinvertebrates, water quality, nutrients, and ecosystem processes) make up the score. Pinto et al. [22] used six water quality parameters, namely, temperature, chlorophyll-a, dissolved oxygen, oxides of nitrogen, suspended solids, and reactive silicates at weekly intervals along the Hawkesbury-Nepean River (HNR) system in South-Eastern Australia to evaluate the human and natural influences on the river system health in a periurban landscape.

China possesses total water resources of 2812.4 billion $\mathrm{m}^{3}$ ranking the 6 th in the world, while its per capita water resource only accounts for a quarter of world average in terms of per capita water resources $[1,3]$. The rapid development results in increasing water requirements and overwhelming amounts of waste discharge, which degrades the water ecosystem. The Weihe River in China is the largest tributary of the Yellow River and plays an important role in developing West China and the maintenance of ecosystem health of the Yellow River [23]. Since the late 1990s, many parts of the river have lost ecosystem functionality and such problems have disturbed the sustainable development of the region [23], which has become a widespread concern in China [24]. Many researchers have conducted studies on ecological environment of the river with significant results [25-27]. For the Weihe River, Shi [28] established healthy controlling indicator system of the Weihe River based on the riverbed, aquatic environment, and socioeconomic functions of the river, while this system lacks specific evaluation and analysis of the results. Feng [29] established the evaluation index system applied to assess the Weihe River health based on the status of environmental issues of the river. However, this evaluation only focuses on flood control and river sediment transport capacity. More recently, Wei et al. [7] developed a complex system dynamics model (SD) to assess socioeconomic impacts of different levels of E-flow allocation in the Weihe River Basin of China, which aims to find an optimal growth pattern considering both socioeconomic growth and E-flow requirements. Li et al. [24] determined the changes in major factors of stream flow, water quality, channel morphology, and riparian vegetation affecting its ecosystem health of the Weihe River. Wu et al. [30] assessed the ecological health of the Weihe River using an index of water and habitat quality (IWHQ) based on environmental variables and habitat quality (QHEI). The study proposed a strategy for sustainable development at a river basin scale, in which water resources should be allocated efficiently, equally, and fairly for socioeconomic development and a healthy river system. However, this study does not analyze and evaluate the current ecosystem health situations of the Weihe River.

This study developed an evaluation index system for the health of the Weihe River in Shaanxi Province, where the Weihe River (Shaanxi section) was divided into five sections based on water function zoning method and then the river health was evaluated section by section. This study improves the indicator evaluation system for river health; the methods and results concerned will provide theoretic and practical support for river health assessment, river development, utilization, and management, and river ecological restoration of the Weihe River.

\section{Study Area Description}

The Weihe River, originating from north of Niaoshu Mountain with an altitude of $3485 \mathrm{~m}$ above sea level, is the largest tributary of the Yellow River. It runs across $818 \mathrm{~km}$ through the provinces of Gansu and Shaanxi and joins the Yellow River from the right bank in the city of Tongguan, from where the Yellow River turns to the east (Figure 1). The drainage area, annual flow flux, and annual sediment discharge of the Weihe River account for $17.9 \%, 16.5 \%$, and $2.5 \%$ of the total amount of the Yellow River Basin, respectively. The channel length in the confluence area is about $13.1 \mathrm{~km}$ [31].

The Weihe River flows across about $502.4 \mathrm{~km}$ with a drainage area of $67,100 \mathrm{~km}^{2}$ in Shaanxi Province where the well-known Guanzhong Plain in Northwest China is located. The river basin plays a great role in social, ecological, and economical development of Shaanxi Province (Figure 1). About $64 \%$ of the population, $56 \%$ of the farmland, $72 \%$ of the irrigation area, and $82 \%$ of gross industrial output value of Shaanxi Province are distributed in this area. And about $81 \%$ of gross domestic product (GDP) of the Shaanxi Province derived from the Weihe River Basin [32]. Xian, the capital of Shaanxi Province, is one of the birthplaces of the ancient Chinese civilization in the Yellow River Basin and the starting point of Silk Road. The total population of the municipality is up to 8.5 million. Known as the leading city of China's Western Development Drive Program since 1990s, Xi'an is an important economic, cultural, industrial, and educational center in central-northwest region [33].

The most important topographic feature of the Weihe River Basin is the Loess Plateau in the north, which is the main source of sediments in the river $[34,35]$. The Jinghe River, the Beiluo River, and the Shichuan River flow into the Weihe River from the Loess Plateau with hyperconcentrated sediments. The topographic feature for the southern part of the Weihe River Basin is the Qinling Mountains, and the precipitation there is the main water supply resource for the river flow. Tributaries of the river from the Qinling Mountains are with less sediment [36].

The climate of the Weihe River Basin in Shaanxi Province is continental, warm, and semihumid controlled by the East Asian monsoon climate [33]. The annual average temperature is about $13.3^{\circ} \mathrm{C}$ and the annual rainfall is in the range of $558-750 \mathrm{~mm}$ with a general increasing trend from north to south. The mean annual precipitation of this basin area is 31.16 billion $\mathrm{m}^{3}$, accounting for $22.4 \%$ of the total precipitation of Shaanxi Province [24]. About 78\% of the rainfall concentrates during May to October, among which the rainfall from July to September accounts for $47 \%$ of the annual total. The mean annual runoff of the basin area is 10.37 billion $\mathrm{m}^{3}$, and 


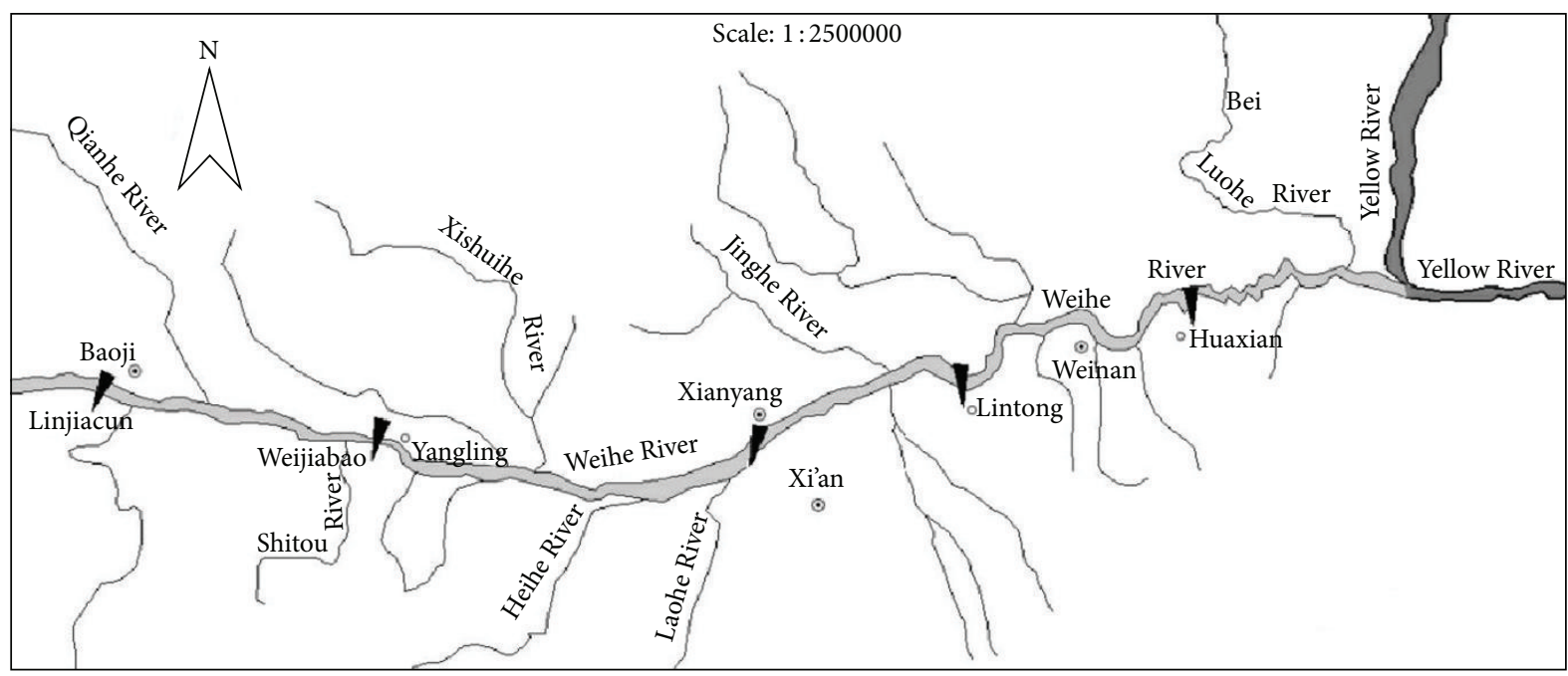

$\odot$ City
$\leftarrow$ River
Gauging station

FIGURE 1: Study area showing hydrological gauging stations.

the mean annual variation coefficient of runoff is about $0.30-$ 0.35 . The runoff discharge patterns are dominated by runoff from July to September, which accounts for about $60-70 \%$ of annual discharge [6].

A large number of groundwater pumping wells were constructed near the river, which potentially reduces the infiltration of river water into the adjacent aquifers of the Weihe River. Agricultural irrigation is the largest water consumer, representing $60 \%$ of the total amount of water consumption, which is withdrawn from the river and aquifers. Even in the low flow period, $80 \%$ of water in the stream is impounded by dams for agriculture irrigation in the Baoji district [24]. The ratio of water utilization volume for domestic, industry, and agriculture makes up $47.9 \%$ to the total volume of water resources in the Weihe River Basin. Meanwhile, the Weihe River Basin has been one of the most serious soil loss areas in the Yellow River Basin. The area suffering from serious soil loss has reached $360,000 \mathrm{~km}^{2}$, taking up $65 \%$ of total land area in the Weihe River Basin, which has not only aggravated the deterioration of ecosystem but also resulted in serious sediment deposition in the lower reach of the Weihe River $[31,37]$. The cumulative yield of sediment deposition was 1.30 billion $\mathrm{m}^{3}$ in 2001, while the maximum amount was 1.32 billion $\mathrm{m}^{3}$ in 1997 (Figure 2). The capacity of the levees to prevent flood in the lower Weihe River decreased from 50-year to 20-year frequency of flooding and further to 10-year flood frequency [31]. The Weihe River streambed was, however, elevated downstream near Tongguan due to accumulation of silt and clay, leading to water logging and increased risk of flooding in this region [38].

In addition, the Weihe River is the major sewage discharge channel in the Guanzhong Region. Large amount of untreated industrial wastewater and domestic sewage is directly discharged into the Weihe River. Also, the nonpoint

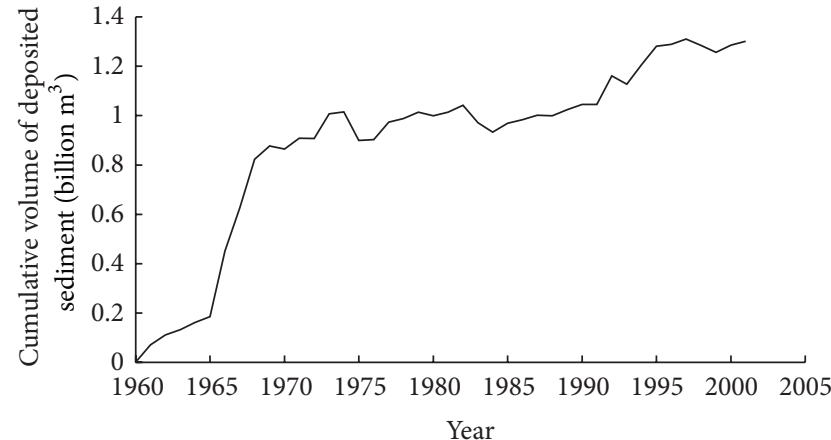

Figure 2: Cumulative volume of deposited sediment in the channel of the lower Weihe River.

source of contaminated stormwater washing off parking lots, roads and highways, and lawns (containing fertilizers and pesticides) is drained into the river. According to the survey data from Shaanxi Provincial Environmental Protection Bureau, a total number of 245 sewage discharge ports are distributed on both sides of the Weihe River, and more than 700 million tons of sewage is discharged into the river annually, which has resulted in serious water pollution [24].

There are five hydrological gauging stations (Linjiacun, Weijiabao, Xianyang, Lintong, and Huaxian) along the Weihe River in Shaanxi Province (Figure 1). Stream gradient becomes gentle from Linjiacun to the mouth of the lower reaches of the Weihe River. The average stream gradients for the reaches of Linjiacun-Xianyang and downstream from Xianyang are $1.24 \mathrm{~m} / \mathrm{km}$ and $0.28 \mathrm{~m} / \mathrm{km}$, respectively [39]. On the basis of data related to ecology, society, economy, hydraulics, and hydrology measured in 2007, a typical hydrological year, the river health for five reaches is estimated, 
including Linjiacun-Weijiabao (LW), Weijiabao-Xianyang (WX), Xianyang-Lintong (XL), Lintong-Huaxian (LH), and the downstream of Huaxian (DH).

\section{Methods}

3.1. Fuzzy Synthetic Evaluation Method. Fuzzy synthetic evaluation method applies fuzzy mathematical principles to evaluate things and phenomenon affected by variety of factors [40, 41]. Fuzzy-based techniques are helpful in addressing deficiencies inherent in binary logic and propagating uncertainties through models. Contrary to binary logic, fuzzybased techniques provide an intensity of exceeding regulated thresholds with the help of memberships to various health levels [42]. The fuzzy synthetic evaluation method regards evaluation objectives as a fuzzy set (named the factor set $U$ ) composed of variety of factors with different assessment levels selected. Another fuzzy set named the evaluation set $V$ is employed to calculate the membership degree of each individual factor in the evaluation set to establish a fuzzy matrix. The quantitative evaluation value of each factor is finally determined by calculating the weight distribution of each factor in evaluation goal. It applies the fuzzy transformation theory and maximum membership degree law and makes a comprehensive evaluation on various factors $[43,44]$. Specific steps are as follows.

Firstly, evaluation factors are defined. In order to obtain accurate assessment results for river health conservation and protection, the factors reflecting the river health are determined based on the following rules. (1) Naturality: The factors reflect the essential attribute of the ecosystem functions of each section for the river [45]. (2) Representativeness: The most significant factor is identified to represent the same categorical ones. (3) Stability and variability: The domain factors can be determined within a certain time even though they change for a larger temporal scale [46]. (4) Quantification: The factors can be valued by the measured data and used to calculate the evaluation of river health. (5) Operability: The quality or function of these factors can be improved through treatment measures by related government agency.

Based on these rules, the main ecosystem function of the Weihe River and the water environmental function zoning of Shaanxi Province was enacted by provincial government in 2004. Factor set of evaluation object is determined, which is expressed by $U=\left\{u_{1}, u_{2}, \ldots, u_{m}\right\}$. It is a set composed of $m$ evaluation indictors, which are defined as follows. (1) Water quality: the major pollutant in the Weihe River is organic pollution including chemical oxygen demand (COD) and ammonia-nitrogen $\left(\mathrm{NH}_{3}-\mathrm{N}\right)$, which are the national pollution indicators classified by environmental quality standards for surface water (GB 3838-2002) defined by the environment protection law of the People's Republic of China. (2) Guaranteed rate of discharge in dry flow season: it is the ratio of average flow volume in the dry flow season to the annual mean flow volume. (3) The ratio of wetland area: it is the percentage of the wetland area to the whole basin area. (4) Recreational value index: it is the ratio of measured in-stream flow to desired flow for supplying recreational activities, such as landscape appreciation, riverine travel. (5) Riparian vegetation coverage ratio: it is the ratio of riparian vegetation (grass, forestland, orchard, shrub, and riparian zone) area to the total riparian land area. (6) Capacity of flood discharge: it is the ratio of actual flood drainage flow to the desired flood drainage flow. (7) Requirement rate of bankfull discharge: it is the ratio of bankfull discharge to critical flow under the conditions without erosion or deposition. (8) Variation rate of streambed gradient: it is the ratio of stream gradient during measured period to the previous gradient before Sanmenxia Reservoir operation. (9) Proportion of fish species: it is the ratio of current fish species amount to amount in the 1980s.

Secondly, remarkable grades of evaluation factors are determined: the rationality of the evaluation criteria directly affects the accuracy of evaluation results. Considering field investigation, expert advice, and literature review, the five remarkable grades including excellent, good, moderate, poor, and sick for the significance of the evaluation factors are defined, which is expressed by set, $V=$ $\left\{v_{1}, v_{2}, v_{3}, v_{4}, v_{5}\right\}$.

Thirdly, the factor weights are determined. The accuracy determination of the factor weight is of great importance to the evaluation of estimation results. Many methods have been developed to calculate factor weight, which can be roughly divided into subjective method and objective method according to the different sources of the original data. Subjective method, such as Delphi method and analytic hierarchy process (AHP), depends on the expert's experience and judgment, and so on. In contrast, objective method, such as principal component analysis method, standard variance method, and maximizing deviation method, is based on measured data and thus has less subjective errors caused by human judgment. Objective ways cannot reflect the subjective requirements of decision-makers though they avoid human interference. This study used AHP, one commonly used method, to evaluate the health of the Weihe River in Shaanxi Province. A formal questionnaire for evaluation factor weights is proposed, the values of which are suggested by researches and governors. Then, the weight for each evaluation factor is determined, which is expressed by $W=\left\{w_{1}, w_{2}, w_{3}, \ldots, w_{m}\right\}$, a set composed of $m$ weight values.

Fourthly, the fuzzy membership function is estimated. There are some commonly used forms of functions to calculate membership degree, such as normal type, partial large-scale, partial small, triangular fuzzy numbers, lower semitrapezoidal, trapezoidal, and ridge [47]. The conclusions for the final analyses are consistent though the forms of these membership functions vary; which membership to select does not affect the study results [48]. In this paper, the triangular fuzzy number membership function was selected to determine the membership degree value of the evaluation factors. Different evaluation degree $U_{i j}$ is measured by the standard value $V_{i j k}$ of each evaluation factor. The membership functions are defined as follows [47, 49]. 
For the first grade $(K=1)$

$$
g(x)= \begin{cases}1, & x \leq v_{k}, \\ \cos ^{2}\left[\left(\frac{x-v_{k}}{v_{k+1}-v_{k}}\right) \times \frac{\pi}{2}\right], & v_{k} \leq x \leq v_{k+1}, \\ 0, & x \geq v_{k+1} .\end{cases}
$$

For the second, third, and fourth grade $(K=2,3,4)$

$$
g(x)= \begin{cases}0, & x \leq v_{k-1}, \\ \sin ^{2}\left[\left(\frac{x-v_{k-1}}{v_{k}-v_{k-1}}\right) \times \frac{\pi}{2}\right], & v_{k-1} \leq x \leq v_{k}, \\ \cos ^{2}\left[\left(\frac{x-v_{k}}{v_{k+1}-v_{k}}\right) \times \frac{\pi}{2}\right], & v_{k} \leq x \leq v_{k+1}, \\ 0, & x \geq v_{k+1} .\end{cases}
$$

For the fifth grade $(K=5)$

$$
g(x)= \begin{cases}0, & x \leq v_{k-1}, \\ \sin ^{2}\left[\left(\frac{x-s_{k-1}}{v_{k}-v_{k-1}}\right)\right], & v_{k-1} \leq x \leq v_{k}, \\ 1, & x \geq v_{k} .\end{cases}
$$

Formulas (1)-(3) are suitable for a factor with less value indicating better quality. But for a factor with greater value indicating better quality, the symbol " $<$ " should be changed to ">" and "> " to "<".

Finally, the hierarchical fuzzy evaluation is calculated. The fuzzy relation matrix $R_{i}$ of each evaluation factor $u_{i}$ for remarkable grade $v_{j}$ can be expressed as follows:

$$
R_{i}=\left[\begin{array}{ccccc}
r_{i 11} & r_{i 12} & r_{i 13} & r_{i 14} & r_{i 15} \\
r_{i 21} & r_{i 22} & r_{i 23} & r_{i 24} & r_{i 25} \\
\vdots & \vdots & \vdots & \vdots & \vdots \\
r_{i j 1} & r_{i j 2} & r_{i j 3} & r_{i j 4} & r_{i j 5} \\
\vdots & \vdots & \vdots & \vdots & \vdots
\end{array}\right]
$$

where $r_{i j k}$ is the judge result of evaluation factor $u_{i}$ to remarkable grade $v_{j}$.

The first-grade fuzzy comprehensive evaluation set $B_{i}$ for the evaluation factor $u_{i}$ to remark $j$ is calculated as follows:

$$
\begin{aligned}
B_{i} & =W_{i} \circ R_{i} \\
& =\left(W_{i 1}, W_{i 2}, \ldots, W_{i j}, \ldots\right)^{\circ}\left[\begin{array}{ccccc}
r_{i 11} & r_{i 12} & r_{i 13} & r_{i 14} & r_{i 15} \\
r_{i 21} & r_{i 22} & r_{i 23} & r_{i 24} & r_{i 25} \\
\vdots & \vdots & \vdots & \vdots & \vdots \\
r_{i j 1} & r_{i j 2} & r_{i j 3} & r_{i j 4} & r_{i j 5} \\
\vdots & \vdots & \vdots & \vdots & \vdots
\end{array}\right] \\
& =\left(B_{i 1}, B_{i 2}, B_{i 3}, B_{i 4}, B_{i 5}\right),
\end{aligned}
$$

where $W_{i j}$ stands for weights of the evaluation factor $u_{i}$ to remark $j$ and "o" is the matrix composite operator. In this paper, considering the effect of input single data on the evaluation results, one of general matrix algorithm performed as $M(\cdot,+)$ operator is used. This can clearly reflect the differences in the membership functions of each evaluation factor for each remarkable grade.

Based on formula (4), the judge decision-making matrix of $m$ evaluation factors is provided as follows:

$$
R=\left[\begin{array}{c}
B_{1} \\
B_{2} \\
\vdots \\
B_{m}
\end{array}\right]=\left[\begin{array}{ccc}
W_{1} & \circ & R_{1} \\
W_{2} & \circ & R_{2} \\
\vdots & & \vdots \\
W_{m} & \circ & R_{m}
\end{array}\right] \text {, }
$$

where $R$ is the fuzzy connection of $U$ to $V$.

Then, the second-grade fuzzy synthetic evaluation set $B$ is determined as

$$
B=W \circ R=\left(b_{1}, b_{2}, b_{3}, b_{4}, b_{5}\right) .
$$

According to the principle of maximum membership degree, the greatest value in the set $B$ indicates river health conditions of the study area.

3.2. Sensitivity Analysis. Sensitivity analysis is a useful method to determine which factors are the key drivers to river health [50]. In general, the methods based on mathematical programming are complex and opaque, which has the disadvantage of providing reference for identification of factor's sensibility. The simplest and most common approach is one-factor-at-a-time (OFAT or OAT), where. To see which parameters are the most sensitive factors to affect this produces on the output [51]. OAT is a measurement process to take out one parameter at a time while keeping the other parameters constant. In comparison with the deviations for the value from the whole parameter, the most sensitive factors are determined [52].

\section{Results and Analysis}

4.1. Definition of River Health Indicators. The reasonability of determining the evaluation indicator will directly affect the evaluation results of river health. Up to now, there has been no cohesive standard to assess the river health in China [20]. Generally speaking, an improper evaluation method will lead to unfair consequences, and the main cause of which is that every district, basin, or river has its distinctive characteristics and uniqueness. Thus, there is no mandatory and probable method to unify the evaluation standard to determine river health [53]. The main objectives of river health evaluation are to explore the main problems of the river health by assessing the current situation of the river and hence to investigate measures for amendment. To achieve these objectives, the evaluation indicators with weight for river health evaluation are determined by hierarchical structure including target layer, criterion layer, and index layer (Table 1). 


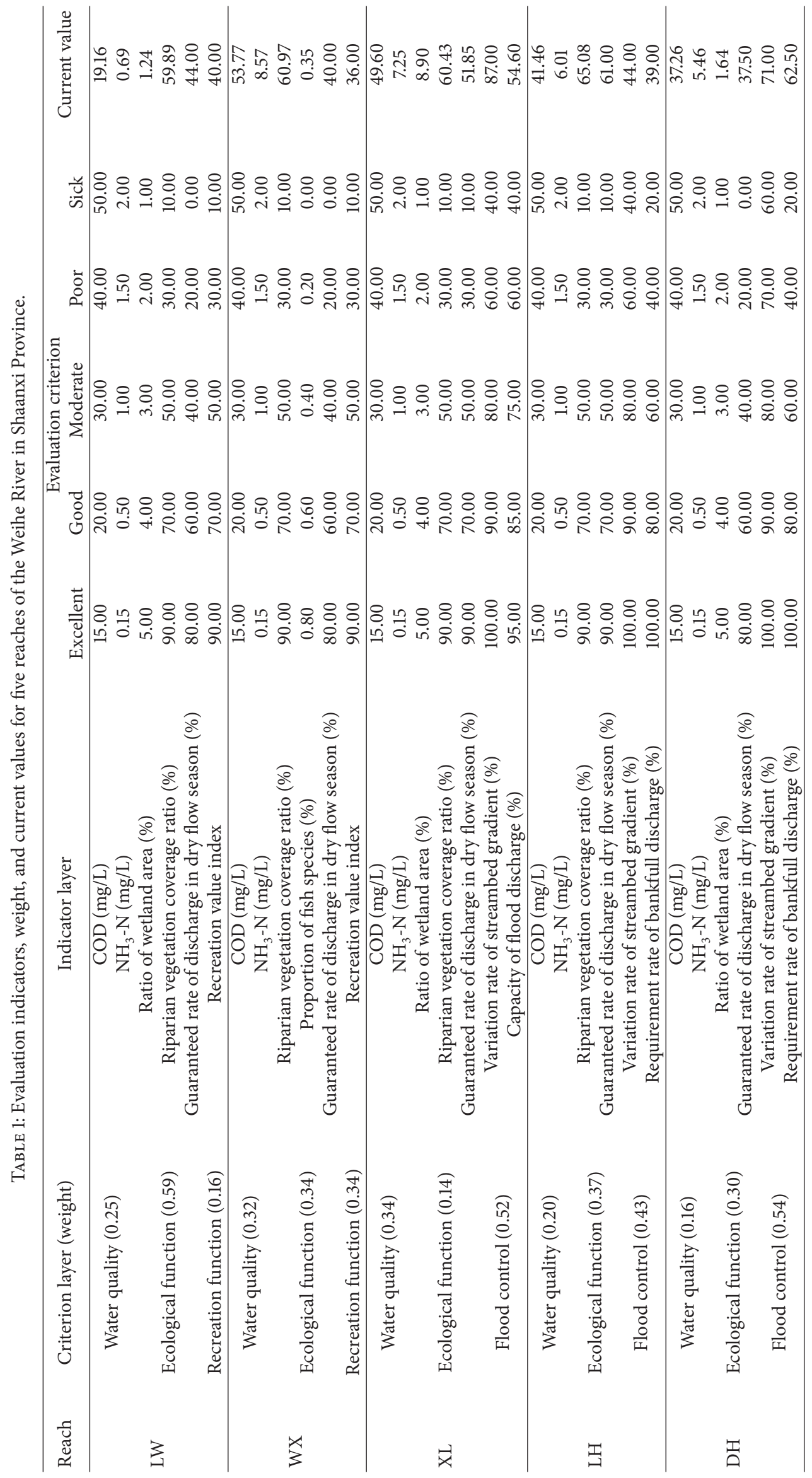


TABLE 2: The evaluation results for the criterion layer of Weihe River in Shaanxi Province.

\begin{tabular}{|c|c|c|c|c|c|c|}
\hline Section & Criterion layer & Excellent & Good & Moderate & Poor & Sick \\
\hline \multirow{3}{*}{ LW } & Water quality & 0.04 & 0.81 & 0.16 & 0.00 & 0.00 \\
\hline & Ecological function & 0.00 & 0.20 & 0.47 & 0.05 & 0.28 \\
\hline & Recreation function & 0.00 & 0.00 & 0.50 & 0.50 & 0.00 \\
\hline \multirow{3}{*}{ WX } & Water quality & 0.00 & 0.00 & 0.00 & 0.00 & 1.00 \\
\hline & Ecological function & 0.00 & 0.19 & 0.76 & 0.05 & 0.00 \\
\hline & Recreation function & 0.00 & 0.00 & 0.21 & 0.79 & 0.00 \\
\hline \multirow{3}{*}{$\mathrm{XL}$} & Water quality & 0.00 & 0.00 & 0.00 & 0.00 & 1.00 \\
\hline & Ecological function & 0.33 & 0.18 & 0.49 & 0.00 & 0.00 \\
\hline & Flood control & 0.00 & 0.40 & 0.11 & 0.42 & 0.09 \\
\hline \multirow{3}{*}{ LH } & Water quality & 0.00 & 0.00 & 0.00 & 0.48 & 0.53 \\
\hline & Ecological function & 0.00 & 0.72 & 0.28 & 0.00 & 0.00 \\
\hline & Flood control & 0.00 & 0.00 & 0.00 & 0.55 & 0.46 \\
\hline \multirow{3}{*}{$\mathrm{DH}$} & Water quality & 0.00 & 0.00 & 0.09 & 0.42 & 0.50 \\
\hline & Ecological function & 0.00 & 0.00 & 0.48 & 0.38 & 0.15 \\
\hline & Flood control & 0.00 & 0.02 & 0.49 & 0.49 & 0.00 \\
\hline
\end{tabular}

4.2. Evaluation Results from Criterion Layer. According to the principle of maximum membership degree and the estimated value from the criterion layer (Table 2), result revealed that that water quality was good in the upstream reach of LW. However, water pollution became very serious in the reaches of WX and XL but got better in the reach below the Lintong gauging station. For the ecological function of the river, the reach of $\mathrm{LH}$ maintained good state while the other four reaches were in a moderate grade. The recreation function for the reaches of LW and WX was poor and the flood controlling capacity for the lower reaches was also in a poor condition. The status of river health for segmented reaches is demonstrated as follows.

(1) Reach of $L W$. In general, water quality is good (Table 3 ), which indicates that the executive measures implemented to control pollutants discharged from industrial and domestic wastewater in recent years were significantly effective. However, the results show that water ecological and recreation functions in the reach were not good. In particular, the ecological function has sick grade, and this mainly resulted from the larger shortage of environmental flow. Due to reduction of precipitation and increase of water use for agriculture irrigation, industry production, and domestic life, the water flow reserved in the stream for maintaining ecological functions has been decreased. Agricultural irrigation is the largest water consumer, accounting for $60 \%$ of the total amount of water consumption. The ratio of water use volume for domestic, industry, and agriculture to the total volume of water resources in the Weihe River Basin runs up to $47.9 \%$. Even in the low flow period, about $80 \%$ of the river flow is impounded by dams for agriculture irrigation in Baoji district (Table 4). Therefore, the guaranteed rate of discharge in dry flow season is very low. Meanwhile, the shortage of incoming water induces a larger area of exposed sediments in river channel, which has been cultivated as farmlands by farmers. The aesthetic value and ecological functions of stream landscape have been deteriorated due to destruction of the connectivity between river and wetland.

(2) Reach of WX. Water pollution is very serious in this river section (Table 3). The concentrations of typical pollutants like chemical oxygen demand (COD) and ammonia-nitrogen $\left(\mathrm{NH}_{3}-\mathrm{N}\right)$ are greater than the upper threshold values in the environmental quality standard based on the surface water function zoning of Shaanxi Province in 2004. A large numbers of lands in Baoji area are cultivated with crops and irrigated by dam water. Water pollutants from nonpoint source of agriculture are the main factors causing serious pollution of the river [24]. This reach is in the moderate level and poor level, respectively, in terms of ecological function and recreation function (Table 3). The coverage ratio of riparian vegetation is high. However, fish species has significantly decreased compared with that of 1980s, which is caused by heavy pollution and great shortage of environmental flow [24]. Moreover, the recreational value has decreased due to loss of aquatic biological diversity and damage of river landscape.

(3) Reach of XL. The pollution of water is also very serious in this reach (Table 3). Most reach pollutants are discharged from industrial wastewater and domestic sewage, especially in Xi'an. The concentration of water pollution is greater than that of aquatic environmental capacity. The ecological functions are in good condition, which are mainly attributed to the large areas of wetland. Meanwhile, the satisfaction degree of water flow for ecological function requirements is high. However, the capacity of flood discharge is low. From the Xianyang hydrological gauging station, channel sedimentation becomes a serious problem, which decreases sediment transport capacity and increases the risks of flood.

(4) Reach of LH. Water quality is poor in this reach (Table 3), especially the most serious pollution of the ammonianitrogen $\left(\mathrm{NH}_{3}-\mathrm{N}\right)$ whose concentration is greater than the 


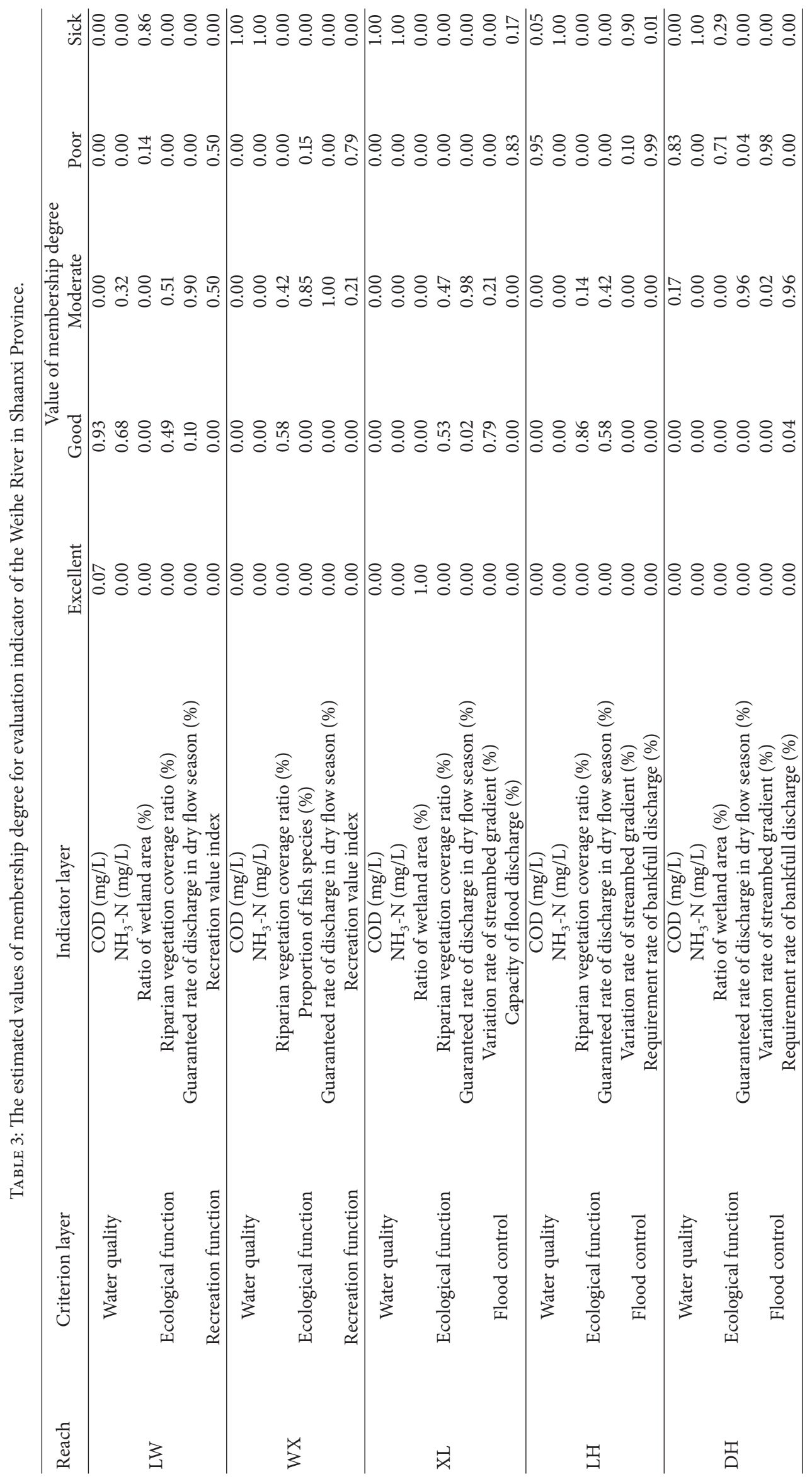


TABLE 4: Comparison of impounding water by dams and the runoff in Baoji area [23].

\begin{tabular}{|c|c|c|c|c|c|c|c|c|c|c|c|c|}
\hline Month & Jan. & Feb. & Mar. & Apr. & May & Jun. & Jul. & Aug. & Sep. & Oct. & Nov. & Dec. \\
\hline Impounding water $\left(10^{6} \mathrm{~m}^{3}\right)$ & 38.0 & 34.5 & 38.8 & 34.0 & 31.0 & 46.2 & 55.3 & 81.6 & 65.9 & 71.0 & 47.2 & 40.1 \\
\hline Runoff $\left(10^{6} \mathrm{~m}^{3}\right)$ & 44.7 & 40.7 & 60.6 & 63.6 & 88.2 & 99.3 & 166.8 & 181.5 & 165.2 & 184.3 & 76.7 & 48.5 \\
\hline Ratio of impounding water to runoff & 0.85 & 0.85 & 0.64 & 0.53 & 0.35 & 0.47 & 0.33 & 0.45 & 0.40 & 0.39 & 0.62 & 0.83 \\
\hline
\end{tabular}

TABLE 5: Health evaluation results of the Weihe River in Shaanxi Province.

\begin{tabular}{ccccccc}
\hline & Reaches & Excellent & Good & Moderate & Poor & Sick \\
\hline & LW & 0.01 & 0.32 & 0.40 & 0.11 & 0.17 \\
River health index (RHI) & WX & 0.00 & 0.06 & 0.33 & 0.29 & 0.32 \\
& XL & 0.05 & 0.23 & 0.13 & 0.22 & 0.39 \\
& LH & 0.00 & 0.27 & 0.10 & 0.33 & 0.30 \\
\hline
\end{tabular}

upper threshold value of heavy pollution grade $V$ in Environmental Quality Standards for Surface Water (GB 3838-2002) defined by the Environment Protection Law of the People's Republic of China. Industrial wastewater and agricultural nonpoint source pollutants are the main sources inducing such heavy water pollution [24]. Both the guaranteed rate of discharge in dry flow season and riparian vegetation coverage ratio are good (Table 3), which maintain well ecological function. However, due to the operation of Sanmenxia Reservoir, the gradual channel sedimentation has resulted in a decrease of stream gradient as well as capacity of bankfull discharge (Table 3).

(5) Reach of $\mathrm{DH}$. Water quality is still bad in this river section though progresses on the treatment of some pollutants have been made. Water quality in terms of chemical oxygen demand (COD) is better in this reach than the above three reaches (Table 3), while concentration of ammonia-nitrogen $\left(\mathrm{NH}_{3}-\mathrm{N}\right)$ is still inferior to the water quality of grade $V$ in environmental quality standards for surface water (GB 38382002). Due to increase of construction and agricultural lands, and shrinking of wetland caused by the decease of river runoff, ecological function has degraded to the moderate grade (Table 3 ). The habitat of aquatic organisms has deteriorated and is in danger of becoming extinct, and wetland ecosystems have been severely damaged. Improper operation of the Sanmenxia Reservoir has reduced the stream gradient of the upper river, which is the direct reason resulting in river channel deposition. Thus reducing elevation and enhancing flood control capacity are the difficulty but also the focus for management and governance of this reach.

4.3. Evaluation Results from Fuzzy Relation Matrix. Membership matrix and the corresponding weights in the evaluation criteria layer of each reach were used to calculate the health situation of the Weihe River in Shaanxi Province (Table 5). According to the principle of maximum membership degree, the maximum level of membership in the healthy level was taken as the river health status of each reach. The maximum degree of membership is in morbid level in the XL reach, indicating that the river health in this reach is in the "sick" rating. The maximum degree of membership in $\mathrm{LH}$ reach is in the "poor" health rating, which suggests that river health in this reach is in poor health status level. The health situation in $\mathrm{DH}$ section is in poor level because the maximum membership degree in this reach is in poor rating. There is no membership degree locating in excellent and good health grating, which reveals that water heath in this reach is less than "moderate" health level. In summary, health status of the Weihe River downstream demonstrated a deteriorating trend along its flowing way, although health situation in the river estuary is improved. In general, the river health of downstream is in a poor rating, which suggests an urgent calling for the protection of the health of the Weihe River.

4.4. Sensitive Indictors for the River Health Evaluation. In this study, the sensitive degree of an indicator to the river health was determined by comparing the difference of measurement values between keeping the whole indicators and taking out of the indicator. Based on the result variation of each indicator before and after being removed, the influence degree, that is, sensitivity degree of the indicator to the health evaluation results of the Weihe River, was determined.

For the reach of LW, the guaranteed rate of discharge in the dry flow season is the most sensitive factor, and the second sensitive factor is the ratio of wetland area (Table 6). This result indicates that the guaranteed rate of discharge in the dry flow season is the most important factor influencing river health of this reach. It suggests that insufficient in-stream flow is the key issue in river health protection in this reach; meanwhile wetland protection should not be neglected.

For the reach of WX, the riparian vegetation coverage ratio, the proportion of fish species, and the guaranteed rate of discharge in the dry flow season had an impact on the results of the river health evaluation in this river section (Table 6). The sensitivity analysis results confirm that the guaranteed rate of discharge in the dry flow season and the proportion of fish species are two factors which could cause the largest variations of the comprehensive evaluation results. However, from the results of a comprehensive evaluation of river health, it is seen that membership in sick levels caused by water quality still remained constant. Thus improving 


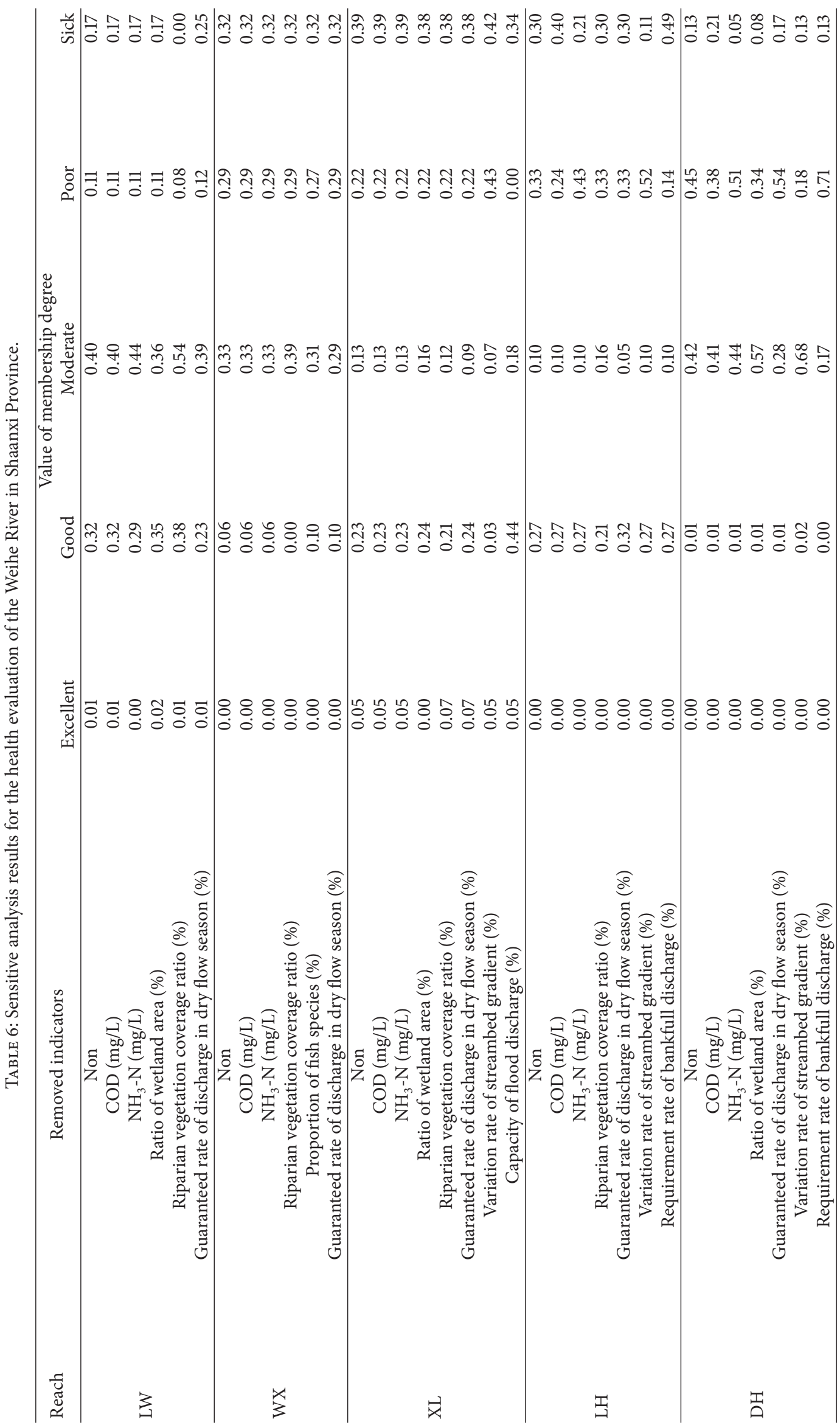


of water quality will definitely lead to the changes of the comprehensive evaluation results of the river health. These analysis results suggest that, in addition to the guaranteed rate in the dry flow season, the impact of the river water quality is the most important factor for river health of this reach; thereby improving water quality is the most important task for the governance of this river section.

For the reach of XL, the indicators that had greater impacts on the comprehensive evaluation results included the riparian vegetation coverage ratio, variation rate of streambed gradient, and capacity of flood discharge (Table 6). The indicator that will affect the evaluation result to the largest extent is capacity of flood discharge, and this is mainly because the Jinhe River with large amounts of sediment transport joins the Weihe River in the reach and the sediments are settled due to reduction of flow velocity here. A large quantity of settled sediments block the channel, which causes flooding, and thus improving flood control capacity including nonstructural measures and engineering measures is the focus for the protection of this reach.

For the reach of LX, pollutant of COD and the requirement rate of bankfull discharge are the most influential factors affecting health evaluation results. In general, the requirement rate of bankfull discharge was slightly more sensitive than COD to the river health (Table 6). The reach is located in the downstream of Xian city, the capital of Shaanxi Province, and its water quality is very poor due to large amounts of sewage and waste discharged from Xian, and many organic pollutants from soil erosion of irrigated agriculture on both sides of the Weihe River. Water pollution control in Xian city is the key issue for water quality improvement in this reach. Reduction of riverbed gradient has resulted in sedimentation settlement, which is the most important reason that led to insufficient requirement rate of bankfull discharge. Another reason for river channel recession is that low peak flows in recent years have not effectively scoured the river channel. These analyses suggest that the river water quality management and river regulation are the most fundamental concerns for river protection and exploitation in the reach.

For the reach of $\mathrm{DH}$, each indicator directly impacts the results of comprehensive health assessment to some extent (Table 6), which suggests that each of these indicators has a certain sensitivity degree to the river health evaluation results in this reach. The sensitive indices in Table 6 display that COD, the ratio of wetland area, and the variation rate of the streambed gradient have large impacts on the comprehensive evaluation results of river health in this reach, among which the variation rate of the stream gradient has the largest impacts. The sediment deposition in the lower Weihe River has been cumulating over 1.3 billion $\mathrm{m}^{3}$ since the Sanmenxia Reservoir was operated in 1960s [24]. Riverbed sedimentation, river channel shrink, and raising of Tongguan elevation every year have gradually reduced the variation rate of the riverbed gradient from $1 / 5000$ before the construction of the reservoir to $1 / 6000$. Difficult sediment transport, pollutant discharge, and exacerbating flood and related wetland loses are the major problems that this reach is facing, which are all caused by the reduction of variation rate of the stream gradient.

\section{Conclusions}

River health is an indicator of the harmony between human and water resources; therefore river health assessment is an important tool for human to develop, utilize, and manage the river in a sustainable way. This study applied a hybrid approach combining AHP and fuzzy comprehensive evaluation to calculate the river health of the Weihe River in China. The results reveal that the reaches of LW and WX were in the "moderate" level of health, and the reaches of LH and DH were in the "poor" health rating, whereas the reach of XL was in the "sick" rating. The key factors which influence the river health are the guaranteed rate of discharge in the dry flow season, water quality, capacity of flood discharge, requirement rate of bankfull discharge, and variation rate of streambed gradient, respectively, for each reach from upper stream to lower stream in the study area.

Many factors in the evaluation process affect the results of river health assessment in varying degrees, such as indicator chosen, index weight determination, basis of reference, and evaluation methods. There are various factors affecting river health, which mainly include natural factors and human disturbance. Natural factors mainly include precipitation decrease, significant reduction in vegetation, and severe soil erosion in the Guanzhong area, which have increased the pressure on flood control in the downstream. As for human disturbance, great increasing of water demand due to rapid development of industry and agriculture and population growth in recent years has greatly aggravated the situation of insufficient river baseflow and even caused river blanking in parts of reaches, which has reduced stream's self-purification capacity and exacerbated water pollution. In general, river health is more intensely affected by human activities, and thus more attention should be paid in aspects of planning water use, water saving, water protection, and promoting harmony between human and water.

The health of the Weihe River is closely related to the benefits of local people in the river basin, and thus the aspects of a healthy river that supplies their basic living needs should be fully investigated and incorporated in the evaluation system. Their concepts and choice of a healthy river are affected by the socioeconomic development situation and their education and awareness. The expectation of river health from local people according to their living needs and so on requires more comprehensive social and economic studies; therefore, it is not included in this study.

\section{Conflict of Interests}

The authors declare that there is no conflict of interests regarding the publication of this paper.

\section{Acknowledgments}

This study is jointly supported by National Natural Science Foundation of China (Grant no. 51379175), Specialized 
Research Fund for the Doctoral Program of Higher Education (Grant no. 20136101110001), Program for Key Science and Technology Innovation Team in Shaanxi Province (Grant no. 2014KCT-27), and Program for New Century Excellent Talents in University (Grant no. NCET-11-1045).

\section{References}

[1] S. Wei, H. Yang, K. Abbaspour, J. Mousavi, and A. Gnauck, "Game theory based models to analyze water conflicts in the Middle Route of the South-to-North Water Transfer Project in China," Water Research, vol. 44, no. 8, pp. 2499-2516, 2010.

[2] D. Zuo, Z. Xu, W. Wu, J. Zhao, and F. Zhao, "Identification of streamflow response to climate change and human activities in the Wei River Basin, China," Water Resources Management, vol. 38, no. 3, pp. 833-851, 2014.

[3] S. Wei and A. Gnauck, "Simulating water conflicts using game theoretical models for water resources management," in Ecosystems and Sustainable Development VI, E. Tiezzi, J. C. Marques, C. A. Brebbia, and S. E. Jørgensen, Eds., pp. 3-12, WIT Press, Southampton, UK, 2007.

[4] R. E. Tharme and J. M. King, Development of the Building Block Methodology for Instream Flow Assessments, and Supporting Research on the Effects of Different Magnitude Flows on Riverine Ecosystems, Water Research Commission, 1998.

[5] V.Smakhtin, C. Revenga, and P. Döll, "Taking into account environmental water requirements in global-scale water resources assessments," Comprehensive Assessment Research Report 2, Comprehensive Assessment Secretariat, Colombo, Sri Lanka, 2004.

[6] J. X. Song, Z. X. Xu, C. M. Liu, and H. E. Li, "Ecological and environmental instream flow requirements for the Wei River-the largest tributary of the Yellow River," Hydrological Processes, vol. 21, no. 8, pp. 1066-1073, 2007.

[7] S. Wei, H. Yang, J. Song, K. C. Abbaspour, and Z. Xu, "System dynamics simulation model for assessing socio-economic impacts of different levels of environmental flow allocation in the Weihe River Basin, China," European Journal of Operational Research, vol. 221, no. 1, pp. 248-262, 2012.

[8] K. Vairavamoorthy, S. D. Gorantiwar, and A. Pathirana, "Managing urban water supplies in developing countries-climate change and water scarcity scenarios," Physics and Chemistry of the Earth, vol. 33, no. 5, pp. 330-339, 2008.

[9] J. J. Kashaigili, K. Rajabu, and P. Masolwa, "Freshwater management and climate change adaptation: experiences from the great Ruaha River catchment in Tanzania," Climate and Development, vol. 1, no. 3, pp. 220-228, 2009.

[10] J. R. Karr and E. W. Chu, "Sustaining living rivers," Hydrobiologia, vol. 422-423, pp. 1-14, 2000.

[11] R. Leete, F. Donnay, S. Kersemaekers, M. Schoch, and M. Shah, Global Population and Water, UNFPA Report on Population and Development Strategies Series, 2003.

[12] F. Sheldon, E. E. Peterson, E. L. Boone, S. Sippel, S. E. Bunn, and B. D. Harch, "Identifying the spatial scale of land use that most strongly influences overall river ecosystem health score," Ecological Applications, vol. 22, no. 8, pp. 2188-2203, 2012.

[13] A. J. Boulton, "An overview of river health assessment: philosophies, practice, problems and prognosis," Freshwater Biology, vol. 41, no. 2, pp. 469-479, 1999.

[14] R. H. Norris and M. C. Thoms, "What is river health?" Freshwater Biology, vol. 41, no. 2, pp. 197-209, 1999.
[15] J. R. Karr, "Defining and measuring river health," Freshwater Biology, vol. 41, no. 2, pp. 221-234, 1999.

[16] T. Oberdorff, D. Pont, B. Hugueny, and J.-P. Porcher, "Development and validation of a fish-based index for the assessment of 'river health' in France," Freshwater Biology, vol. 47, no. 9, pp. 1720-1734, 2002.

[17] R. A. A. Noble, I. G. Cowx, D. Goffaux, and P. Kestemont, "Assessing the health of European rivers using functional ecological guilds of fish communities: standardising species classification and approaches to metric selection," Fisheries Management and Ecology, vol. 14, no. 6, pp. 381-392, 2007.

[18] D. Pont, B. Hugueny, and C. Rogers, "Development of a fishbased index for the assessment of river health in Europe: the European Fish Index," Fisheries Management and Ecology, vol. 14, no. 6, pp. 427-439, 2007.

[19] A. Chakona, C. Phiri, T. Chinamaringa, and N. Muller, "Changes in biota along a dry-land river in northwestern Zimbabwe: declines and improvements in river health related to land use," Aquatic Ecology, vol. 43, no. 4, pp. 1095-1106, 2009.

[20] W. Meng, N. Zhang, Y. Zhang, and B. Zheng, "Integrated assessment of river health based on water quality, aquatic life and physical habitat," Journal of Environmental Sciences, vol. 21, no. 8, pp. 1017-1027, 2009.

[21] C. N. Magagula, A. B. Mansuetus, and J. O. Tetteh, "Ecological health of the Usuthu and Mbuluzi rivers in Swaziland based on selected biological indicators," African Journal of Aquatic Science, vol. 35, no. 3, pp. 283-289, 2010.

[22] U. Pinto, B. L. Maheshwari, and R. L. Ollerton, "Analysis of longterm water quality for effective river health monitoring in periurban landscapes-a case study of the Hawkesbury-Nepean river system in NSW, Australia," Environmental Monitoring and Assessment, vol. 185, no. 6, pp. 4551-4569, 2013.

[23] S. Wei, J. X. Song, and N. I. Khan, "Simulating and predicting river discharge time series using a wavelet-neural network hybrid modelling approach," Hydrological Processes, vol. 26, no. 2, pp. 281-296, 2012.

[24] Q. Li, J. X. Song, A. Wei, and B. Zhang, "Changes in major factors affecting the ecosystem health of the Weihe River in Shaanxi Province, China," Frontiers of Environmental Science and Engineering, vol. 7, no. 6, pp. 875-885, 2013.

[25] G. Y. Li, "Keeping the yellow river healthy," in Proceedings of the 9th International Symposium on River Sedimentation, pp. 18-21, Yichang, China, 2004.

[26] C. M. Liu and X. Y. Liu, "Healthy river and its indication, criteria and standards," Journal of Geographical Sciences, vol. 19, no. 1, pp. 3-11, 2009.

[27] Y. W. Zhao and Z. F. Yang, "Integrative fuzzy hierarchical model for river health assessment: a case study of Yong River in Ningbo City, China," Communications in Nonlinear Science and Numerical Simulation, vol. 14, no. 4, pp. 1729-1736, 2009.

[28] C. W. Shi, "Healthy controlling indicator system of the Weihe River," Yellow River, vol. 33, no. 1, pp. 12-14, 2011 (Chinese).

[29] P. L. Feng, "Assessment indicator for the river health of the Weihe River," Yellow River, vol. 27, no. 8, pp. 3-6, 2005 (Chinese).

[30] W. Wu, Z. Z. Xu, X. W. Yin, and D. P. Zuo, "Assessment of ecosystem health based on fish assemblages in the Wei River basin, China," Environmental Monitoring and Assessment, vol. 186, no. 6, pp. 3701-3716, 2014.

[31] J.-Y. Li, C.-W. Shi, X.-B. Xu, and Z.-J. Fu, "Mechanism and effect of channel evolution at estuary of Weihe River to Huanghe River," Chinese Geographical Science, vol. 16, no. 2, pp. 122-126, 2006. 
[32] Y. Tong, L. X. Fan, and L. H. Cao, "Identification of water environment in Wei River basin," China Resources Comprehensive Utilization, vol. 30, no. 7, pp. 43-45, 2012 (Chinese).

[33] D. P. Zuo, Z. Z. Xu, D. Z. Peng et al., "Simulating spatiotemporal variability of blue and green water resources availability with uncertainty analysis," Hydrological Processes, 2014.

[34] H. Wang and Z. H. Zhang, "Regulation on runoff and sediment discharge of main branches located in Wei River valley and benefits of runoff and sediment decrease under control measures of soil and water conservation," Bulletin of Soil and Water Conversation, vol. 15, no. 4, pp. 55-59, 1995 (Chinese).

[35] F. Z. Chen, M. Y. Dai, and Q. Q. Wu, "Analysis on variation and characteristic of water and sediment in the Wei River," Yellow River, vol. 21, no. 8, pp. 16-18, 1999 (Chinese).

[36] J. X. Song, Z. X. Xu, Y. H. Hui, H. E. Li, and Q. Li, "Instream flow requirements for sediment transport in the lower Weihe River," Hydrological Processes, vol. 24, no. 24, pp. 3547-3557, 2010.

[37] G. E. Wang, L. Ji, and Y. J. Li, "Effect of water and sediment variation on erosion and deposition of the Weihe River bed," Journal of Sediment Research, vol. 4, pp. 49-52, 2001 (Chinese).

[38] X. H. Chen, H. C. Mi, H. M. He et al., "Hydraulic conductivity variation within and between layers of a high floodplain profile," Journal of Hydrology, vol. 515, no. 16, pp. 147-155, 2014.

[39] X. Z. Lin, N. Q. Jiang, Z. Y. Liang, and D. J. Yue, Study on Instream Flow Requirement for Transportation of Sediment in the Lower Wei River, The Yellow River Press, 2005, (Chinese).

[40] R. Sadiq, T. Husain, B. Veitch, and N. Bose, "Risk-based decision-making for drilling waste discharges using a fuzzy synthetic evaluation technique," Ocean Engineering, vol. 31, no. 16, pp. 1929-1953, 2004.

[41] F. Li, W. Wang, Y. Shi, and C. Jin, "Fuzzy synthetic evaluation model based on the knowledge system," International Journal of Innovative Computing, Information and Control, vol. 9, no. 10, pp. 4073-4084, 2013.

[42] R. Sadiq and M. J. Rodriguez, "Fuzzy synthetic evaluation of disinfection by-products-a risk-based indexing system," Journal of Environmental Management, vol. 73, no. 1, pp. 1-13, 2004.

[43] Y. Zhang, Methodology and Application of Fuzzy Mathematics, Coal Industry Press, Beijing, China, 1992, (Chinese).

[44] N.-B. Chang, H. W. Chen, and S. K. Ning, "Identification of river water quality using the fuzzy synthetic evaluation approach," Journal of Environmental Management, vol. 63, no. 3, pp. 293305, 2001.

[45] M. J. Feio, T. Alves, M. Boavida, A. Medeiros, and M. A. S. GraçA, "Functional indicators of stream health: a river-basin approach," Freshwater Biology, vol. 55, no. 5, pp. 1050-1065, 2010.

[46] J. X. Song and H. E. Li, Ecological and Environmental Water Requirements for the Wei River, China Water Conservancy and Electronic Power, Beijing, China, 2004 (Chinese).

[47] X. H. Xue and X. G. Yang, "Seismic liquefaction potential assessed by fuzzy comprehensive evaluation method," Natural Hazards, vol. 71, no. 3, pp. 2101-2112, 2014.

[48] Y. Wang, W. Yang, M. Li, and X. Liu, "Risk assessment of floor water inrush in coal mines based on secondary fuzzy comprehensive evaluation," International Journal of Rock Mechanics and Mining Sciences, vol. 52, pp. 50-55, 2012.

[49] F. Xie and D. S. Tang, "The application of AHP and fuzzy comprehensive evaluation in harmonious level measurement between human and water in city," Journal of Computational Information Systems, vol. 6, no. 14, pp. 4647-4656, 2010.
[50] D. G. Cacuci, M. Ionescu-Bujor, and I. M. Navon, Sensitivity and Uncertainty Analysis, Volume II: Applications to Large-Scale Systems, CRC Press, Boca Raton, Fla, USA, 2005.

[51] J. M. Murphy, D. M. H. Sexton, D. N. Barnett et al., "Quantification of modelling uncertainties in a large ensemble of climate change simulations," Nature, vol. 430, no. 7001, pp. 768-772, 2004.

[52] A. Saltelli and P. Annoni, "How to avoid a perfunctory sensitivity analysis," Environmental Modelling and Software, vol. 25, no. 12, pp. 1508-1517, 2010.

[53] Y. Feng, B. Kang, and L. Yang, "Feasibility analysis of widely accepted indicators as key ones in river health assessment," Journal of Geographical Sciences, vol. 22, no. 1, pp. 46-56, 2012. 

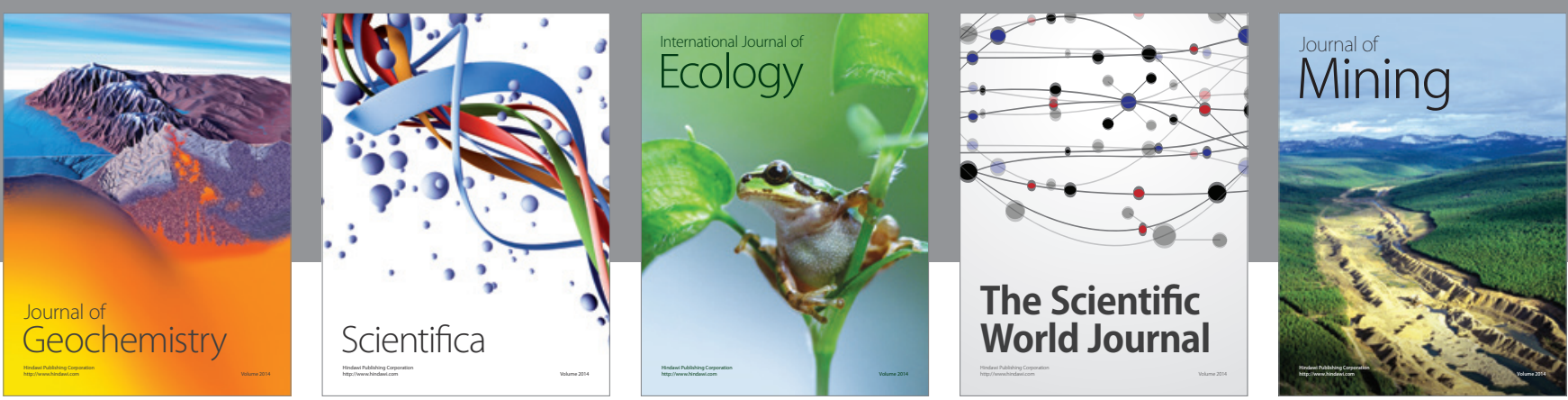

The Scientific World Journal
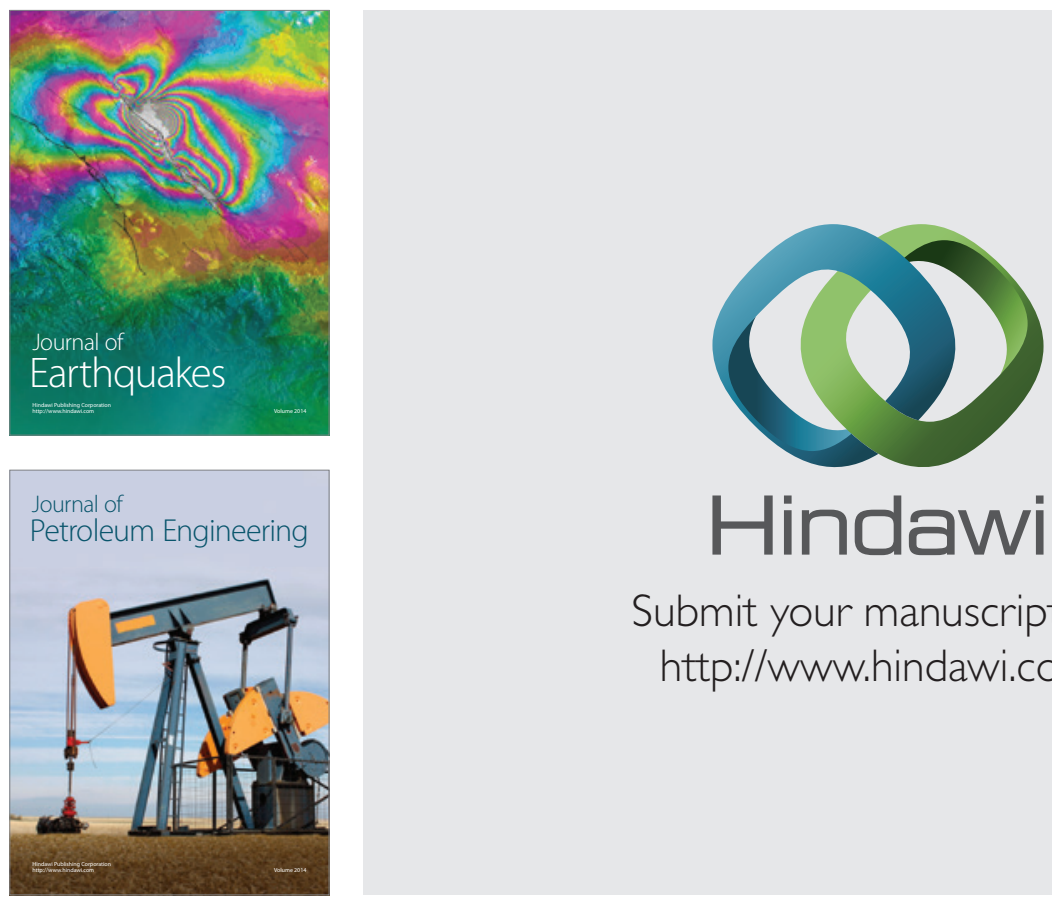

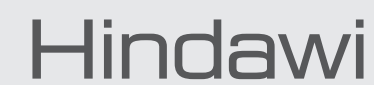

Submit your manuscripts at

http://www.hindawi.com
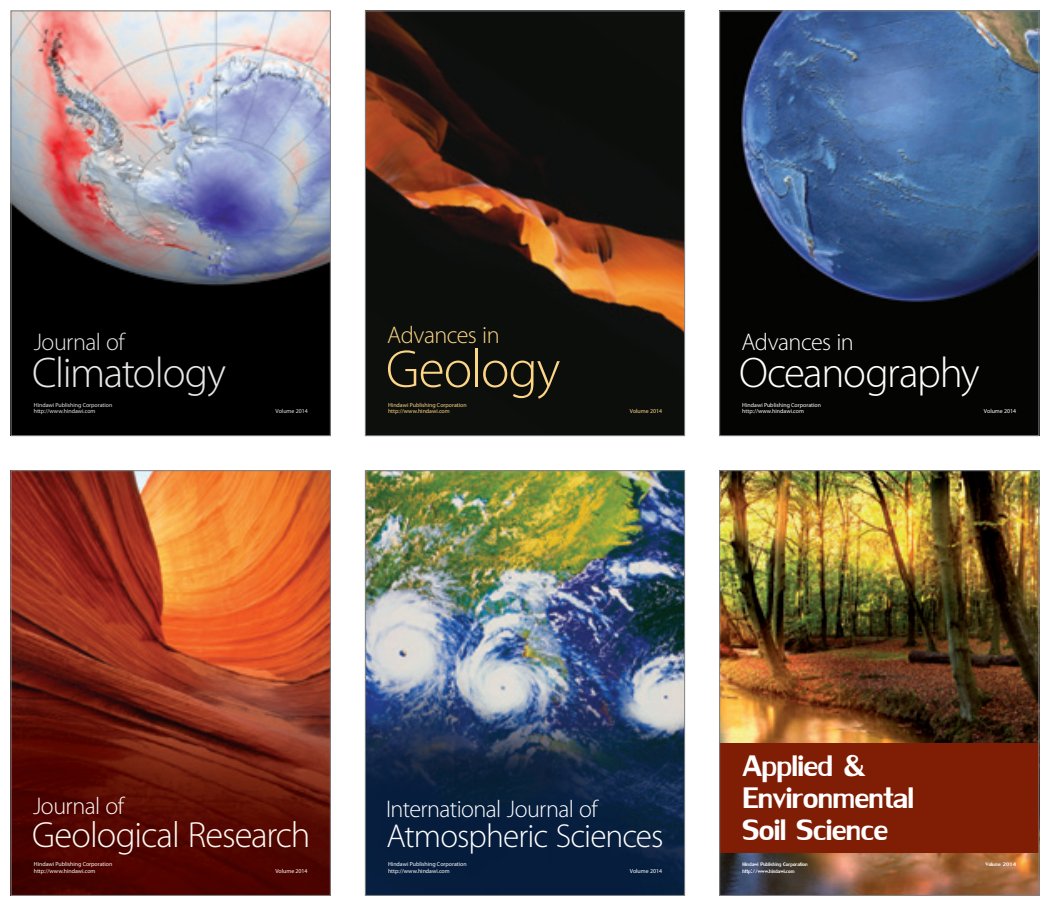
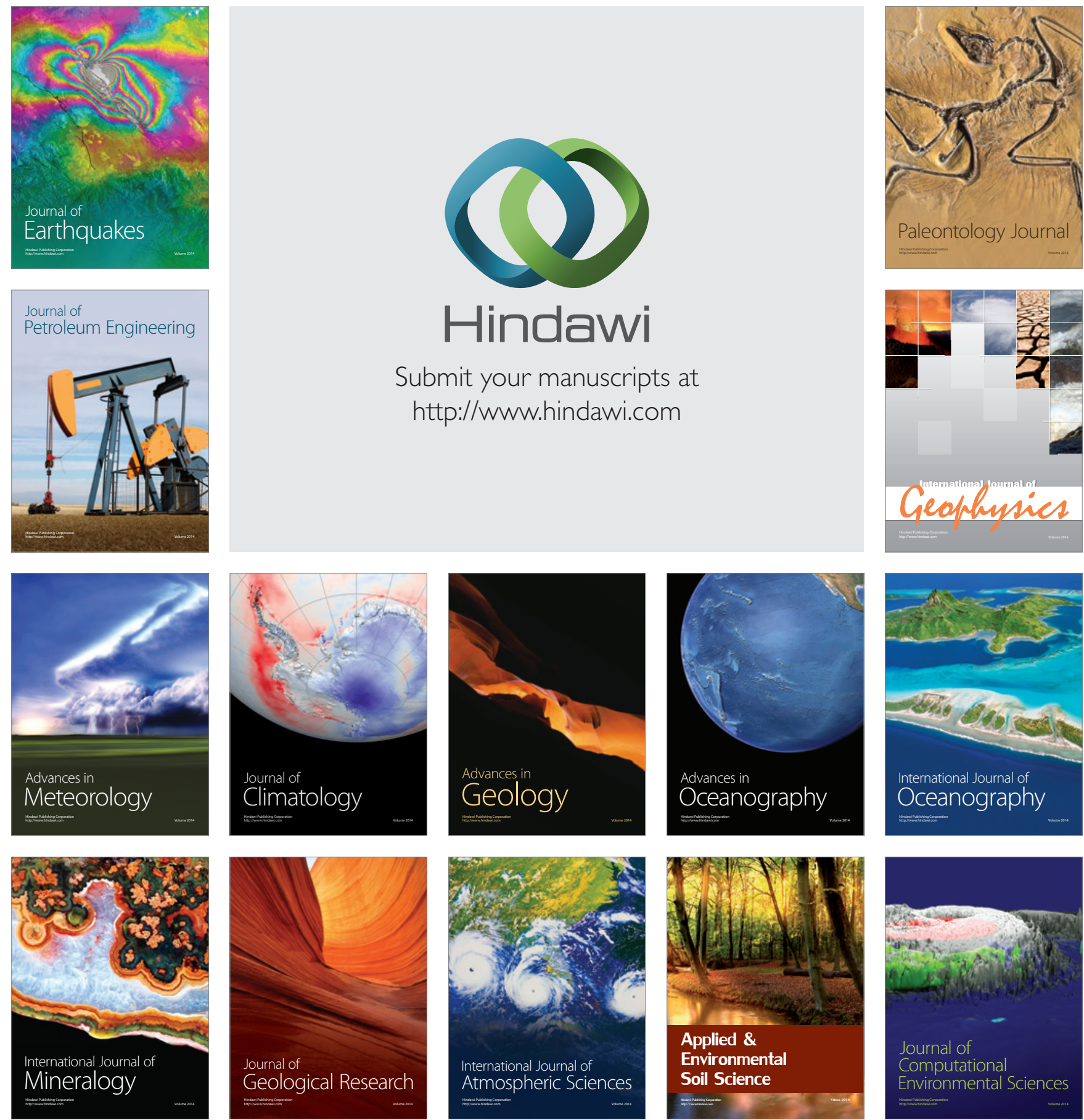